\title{
Endogrupo versus Exogrupo: o papel da identidade social nas relações intergrupais
}

\section{Ingroup versus outgroup: the role of social identity in intergroup relations}

\section{Endogrupo versus exogrupo: el papel de la identidad social en las relaciones intergrupales}

\author{
Sheyla Christine Santos Fernandes* \\ Universidade Federal de Alagoas - UFAL, Maceió, Alagoas, Brasil \\ Marcos Emanoel Pereira** \\ Universidade Federal da Bahia - UFBA, Salvador, Bahia, Brasil
}

\begin{abstract}
RESUMO
Neste artigo é apresentada uma discussão acerca da importância da teoria da identidade social para os estudos sobre as relações intergrupais, com interesse especial nos fenômenos do preconceito e da discriminação. Três questões foram desenvolvidas para guiar a discussão: (1) de que forma ocorre o desenvolvimento da pertença grupal?; (2) em que medida esse sentimento de pertença seria responsável por desenvolver a rejeição em direção a outros grupos e o favoritismo frente ao próprio grupo?; (3) esses processos podem ser utilizados para explicar o preconceito e a discriminação social? Como base para argumentação, utiliza-se a identidade social articulada aos processos de categorização e comparação social, estando a identidade situada no centro de todo processo inerente às relações intergrupais.
\end{abstract}

Palavras-chave: identidade, preconceito, discriminação.

\begin{abstract}
This article provides a discussion about the importance of social identity theory to the study of intergroup relations, with special interest in the phenomena of prejudice and discrimination. Three questions were developed to guide the discussion: (1) how is the development of group belonging?; (2) how is the extent this feeling of belonging would be responsible for developing the rejection against other groups and favoritism toward the group itself ?; (3) these processes can be used to explain prejudice and social discrimination? As a basis for argument, social identity is articulate to categorization processes and social comparison is use, with the identity in the center of the whole process inherent to intergroup relations.
\end{abstract}

Keywords: identity, prejudice, discrimination.

\section{RESUMEN}

Este artículo muestra una discusión acerca de la importancia de la teoría de la identidad social para el estudio de las relaciones intergrupales, con 
especial interés en los fenómenos de los prejuicios y la discriminación. Tres preguntas fueron desarrolladas para guiar la discusión: (1) cómo es el desarrollo del sentimiento de pertenencia grupal?; (2) en qué medida este sentimiento de pertenencia sería responsable de desarrollar el rechazo hacia otros grupos y el favoritismo frente el grupo en sí ? ; (3), estos procesos pueden ser utilizados para explicar el prejuicio y la discriminación social? Como base para la discusión, se utiliza la identidad social articulada a los procesos de categorización y comparación social, con la identidad en el centro de todo el proceso inherente a las relaciones intergrupales.

Palabras clave: identidade, prejuicio, discriminación.

“Todos os animais são iguais, mas alguns animais são mais iguais que outros" (A revolução dos bichos, George Orwell, 1945).

George Orwell apresenta em sua fábula, A revolução dos bichos, a luta pelo ideal de liberdade e igualdade entre os animais (contra os humanos) a fim de estabelecer um sistema igualitário em que não houvesse mais a dominação dos bichos pelos humanos. A partir da efetivação da revolução detalhadamente organizada e comandada pelos porcos, reconhecidos como os mais inteligentes dentre os animais, em um arroubo de revolta por conta dos maus tratos e da falta de alimentos, os animais tomam o poder na Granja Solar, expulsando assustadoramente os humanos daquela pequena comunidade. Com o poder nas mãos, após uma intensa comemoração e consequente calmaria frente à harmonia conquistada, os porcos tratam de subverter as normas em prol de seu pequeno grupo. Ocorre então o destino da natureza desigual dos grupos: uns poucos no poder e muitos subordinados. O mandamento utilizado como slogan para a revolução dos bichos contra os humanos, "todos os animais são iguais" (Orwel, 1945, p. 27), já não fazia mais sentido. Ao passo que o poder é atingido, alguns se tornaram "mais iguais que outros" (Orwel, 1945, p. 135) e assim passaram a receber determinados privilégios. Contudo, a perspectiva de ameaça humana de retorno ao poder cessa qualquer tipo de descontentamento por parte de alguns destes subordinados e se vive por um tempo nesta granja como se a igualdade existisse de fato.

Podemos observar dois pontos importantes abordados na fábula de Orwell sobre as relações intergrupais: (1) a forte adesão que os integrantes de um grupo apresentam a partir da existência de um grupo rival, sobretudo, quando o grupo em questão é oprimido pelo grupo dominante; e (2) o favoritismo endogrupal, em que o próprio grupo é beneficiado em detrimento de um outro grupo externo. Nessa perspectiva, assinalamos três questionamentos que guiam a discussão apresentada neste artigo: (1) de que forma ocorre o desenvolvimento da pertença grupal?; (2) em que medida esse 
sentimento de pertença seria responsável por desenvolver a rejeição em direção a outros grupos e o favoritismo frente ao próprio grupo?; (3) esses processos podem ser utilizados para explicar o preconceito e a discriminação social?

\section{Relações intergrupais: o pontapé inicial para a discussão}

Apesar de ser um tema amplamente discutido pela filosofia, sociologia e antropologia, do ponto de vista da psicologia social, as relações intergrupais fazem parte de sua agenda há um tempo relativamente recente (Costa, 2009). Um dos primeiros trabalhos a analisar as relações intergrupais e sua ligação com processos de discriminação social foi desenvolvido por Kurt Lewin (1997/1941), tendo contribuído substancialmente para a formulação posterior da teoria da identidade social. Este autor discute questões teóricas sobre discriminação social por meio da observação e análise dos acontecimentos sociais e movimentos sociais da década de 30, na Europa e nos EUA, especificamente, sobre questões referentes ao antissemitismo, luta das mulheres e dos negros pelo direito ao voto (Lewin, 1997/1941). O interesse de Lewin estava nas práticas de socialização e nas dinâmicas inter e intragrupais utilizadas pelos membros de grupos desprivilegiados face o cenário de discriminação do qual eram alvo. Suas contribuições foram utilizadas por Tajfel (1979), permitindo o desenvolvimento de teorizações mais sistemáticas sobre as relações intergrupais. De modo geral, Lewin dá ênfase ao caráter social do antissemitismo, situando-o em forças externas ao grupo discriminado e independente do comportamento ou características de seus membros. Acrescenta ainda que os pensamentos negativos relativos ao grupo de pertença dão origem a estratégias de adaptação ao grupo dominante e também ao grupo dominado. No entanto, esse processo de adaptação, segundo essa perspectiva, não se traduz em uma mudança efetiva no sistema social, visto que o grupo dominado, normalmente, assimila os valores do grupo dominante, como é o caso das análises em relação ao antissemitismo. Nessa perspectiva, o grupo dominado seria uma entidade subjetivamente formulada, capaz de integrar seus membros a partir de um destino comum, o que por consequência retira dos seus membros a distintividade individual (Cabecinhas, 2002a).

Allport (1962) apresenta em sua análise sobre o preconceito, a noção de generalização das características do grupo alvo como sendo uma das bases da categorização. Neste aspecto, essa ausência de distintividade individual percebida no grupo dominado gera no grupo dominante uma autonomia que não é capaz de ser experienciada pelo grupo dominado, resultando na manutenção das relações assimétricas de poder entre os grupos. É neste sentido que Allport 
insere o processo de estereotipização e rotulação na discussão sobre as relações intergrupais e enfatiza que a categoria, ou seja, o rótulo linguístico e o estereótipo fazem parte de um processo mental complexo, em que um estereótipo não pode ser idêntico a uma categoria, mas pode ser compreendido como uma ideia fixa que acompanha a categoria. O estereótipo atua, por sua vez, como um recurso justificatório para a aceitação ou rejeição categórica de um grupo e como recurso seletivo que assegura a manutenção da simplicidade no julgamento (Allport, 1962).

Em termos de uma reflexão sobre as contribuições seminais de Lewin e de Allport, podemos indicar que, se por um lado o primeiro autor enfatizava o caráter social das relações intergrupais entre grupos dominados e grupos dominantes, por outro lado, Allport focalizava sua análise do preconceito com base, principalmente em aspectos cognitivos, como falha cognitiva, processo de categorização, embora tenha salientado a natureza multifocal deste fenômeno. Deste modo, é possível supor a existência de uma articulação entre fenômenos de ordem intrapsíquica e social na base da construção das configurações derivadas das relações sociais. E são essas configurações que guiam o comportamento social.

Outro teórico que também contribuiu para o estudo das relações intergrupais foi Sherif (1961). Seus estudos realizados entre as décadas de 1950 e 1960 foram promissores em introduzir na psicologia social os primeiros passos para o entendimento dos conflitos intergrupais (Gaertner \& Dovidio, 2000).

Em um estudo denominado "Robbers Cave", Sherif (1961) analisou as interações naturais de dois grupos de meninos em um acampamento de verão. Por uma semana, os grupos conviviam separadamente a fim de fortalecer as normas intragrupais. $\mathrm{Na}$ semana seguinte, os grupos eram colocados em situação de competição por meio de atividades esportivas. Por fim, na terceira semana, os grupos mantinham contato em situação neutra. Os resultados demonstraram dados interessantes sobre a formação de normas e a emergência de uma hierarquia dentro dos grupos. Na situação de competição, houve o surgimento de estereótipos e de hostilidade entre os grupos. Na situação neutra, embora não competindo entre si, a hostilidade entre os grupos não foi reduzida. Apenas após a intervenção dos pesquisadores, introduzindo metas que não poderiam ser atingidas sem a cooperação de ambos os grupos, as relações intergrupais vieram a se tornar mais harmoniosas (Gaertner \& Dovidio, 2000).

O modelo de Sherif (1961) estipulava que os comportamentos hostis entre os grupos, bem como, as representações que favorecem o endogrupo em relação ao exogrupo, resultam da situação de conflito e não das características ou estruturas internas do grupo e seus membros. As evidências indicam que tais comportamentos são 
resultantes da identificação dos membros com seu grupo, o que coloca a identidade social no centro das relações intergrupais (Neto \& Amâncio, 1997).

Levine e Campbell (1972), pioneiros a contribuírem com o estudo sobre conflito intergrupal, definiram essas considerações advindas dos estudos de Sherif como um conflito realista (propondo posteriormente o modelo do conflito realista), tendo em vista que os conflitos intergrupo foram gerados por condições de conflito reais, por isso, a denominação de conflito de interesses grupais. No entanto, para Tajfel e Turner (1979), os dados obtidos nas investigações de Sherif, apesar de levantarem importantes constatações sobre 0 comportamento intergrupal, deixam a desejar no sentido em que negligenciam a identificação dos participantes com seu grupo de pertença como determinante central na análise do comportamento intergrupal. A identificação com o próprio grupo foi tomada neste modelo como um fenômeno derivado apenas dos conflitos gerados no grupo.

Para Sherif (1961), a competição entre os grupos pode aumentar a coesão dos membros e a cooperação dentro do grupo, isto é, os conflitos intergrupais não apenas geram sentimentos antagônicos em relação ao exogrupo, mas podem proporcionalmente desenvolver dentro do próprio grupo sentimentos favoráveis que ampliam a satisfação com a pertença grupal (Cikara, Botvinick, \& Fiske, 2011). Contudo, a identidade social não é aludida como um fenômeno autônomo, mas secundário, ponto que para Tajfel e Turner (1979) é crucial no entendimento das relações intergrupais. Para esses autores, o desenvolvimento das identificações com o grupo de pertença é entendido na teoria do conflito realista basicamente como um epifenômeno do conflito intergrupal. Para a teoria do conflito realista, essas identificações aparecem ligadas a alguns padrões das relações intergrupais, mas não é apresentado um suporte em termos do processo que está por trás do desenvolvimento e manutenção da identidade grupal nem sobre o possível papel autônomo sobre os aspectos subjetivos do comportamento endogrupal e intergrupal dos membros do grupo (Tajfel \& Turner, 1979).

Desta forma, Tajfel e Turner (1979) defendem uma orientação teórica que possa ampliar esses achados, colocando a identidade social no centro do processo inerente às relações intergrupais e conflitos intergrupais. Inicia-se, então, uma longa jornada de investigações que se tornaram um marco no estudo do preconceito e discriminação através dos pressupostos da teoria da identidade social (Jenkins, 2014). 


\section{I dentidade social: um marco no entendimento das relações sociais}

A identidade social emerge como tema de estudo na década de 50 com a publicação de um trabalho sobre percepção categorial realizado por Henry Tajfel. As origens da teoria da identidade social podem ser buscadas em uma concepção gestaltista da percepção que, a princípio permitiu a Tajfel propor um modelo de acentuação relativa dos contrastes. Com a ampliação de seu modelo abordando os efeitos da categorização na percepção e nos estudos dos estereótipos sociais, Tajfel inicia seus estudos sobre a discriminação e se torna um marco no estudo das relações intergrupais (Doise, 2002).

Scandroglio, Martínez e Sebastián (2008) enfatizam que a teoria desenvolvida por Tajfel e ampliada por seus colaboradores tem grande influência na psicologia social por proporcionar notáveis contribuições à dimensão social do comportamento, em relação ao comportamento grupal em geral, e às relações intergrupais, em particular.

Para Tajfel (1981), a identidade social pode ser definida como o conjunto formado pelo autoconceito do indivíduo, sua pertença grupal e a valoração atribuída a esta pertença. Neste sentido, o pressuposto central de Tajfel defende que, por mais que seja complexa a visão de si próprio em relação ao mundo físico e social, certos aspectos dessa visão constituem uma importante contribuição de sua pertença a determinados grupos ou categorias sociais. Dentre essas pertenças, umas aparecem mais salientes que outras, sendo fundamental a estima subjetiva dessas pertenças sobre os aspectos do comportamento do indivíduo pertinentes às relações intergrupais (Christian, Bagozzi, Abrams, \& Rosenthal, 2012). Nesta perspectiva intergrupal da identidade social, a categorização social é inserida como fator central modulador da identidade (ver Tajfel, 1981; Amâncio, 1993; Cabecinhas, 2002b).

A categorização social pode ser entendida como "um sistema de orientação que ajuda a criar e a definir o lugar do indivíduo na sociedade" (Tajfel, 1981, p 291), ou seja, uma representação cognitiva da estrutura social colocada a partir de grupos ou categorias, portanto, um elemento que desempenha o papel de definir em termos mais gerais o auto-reconhecimento do indivíduo.

Cabecinhas e Lázaro (1997) enfatizam esse caráter funcional do processo de categorização social quando concebem este fenômeno como um processo capaz de segmentar, classificar e ordenar o ambiente social, servindo como um balizador do lugar do indivíduo no mundo e na sociedade. Neste sentido, a identidade social é relacional e comparativa na medida em que é a comparação do lugar do indivíduo no mundo por meio desta classificação em termos de 
categorias, em outras palavras, a pertença deste indivíduo ao grupo ou grupos em relação aos demais grupos sociais, que lhe confere sua identidade (Chen \& Chen, 2011). O processo de categorização social permite que generalizações e hipersimplificações sejam realizadas em direção a certas categorias e isso constitui uma das bases da formação dos estereótipos (Brasil \& Cabecinhas, 2014).

Segundo Tajfel (1981), várias consequências no nível da pertença grupal podem ser pontuadas a partir do reconhecimento da identidade em termos socialmente definidos, dentre elas, (1) pode-se supor que uma pessoa tenderá a se manter como membro de um grupo ou a procurar pertencer a novos grupos se esses contribuírem para os aspectos positivos da sua identidade social; (2) se o grupo não preenche esse requisito, a pessoa tenderá a abandoná-lo, a não ser que não seja possível abandonar esse grupo ou o abandono represente um conflito de valores importantes para a auto-imagem da pessoa; (3) se o abandono do grupo possui essas dificuldades, então, duas soluções podem ser tomadas: mudar a interpretação pessoal dos atributos do grupo, de modo que seus defeitos se tornem aceitáveis ou aceitar a situação e se empenhar em ações que possam melhorar o status do grupo; (4) nenhum grupo vive isolado, a comparação entre os grupos é o que leva a esta análise dos atributos do grupo. É justo esta comparação social que estabelece a ligação entre a categorização social e a identidade social para Tajfel.

Iñiguez (2001) discute essa perspectiva relacional da identidade social considerando que o que de fato se apresentar como relevante nesse domínio se refere à dimensão experiencial da identidade inserida no contexto social de nossas relações e interações com os demais, sendo a identidade, acima de tudo, um dilema entre a singularidade e similitude entre nós e os outros em termos de modos de agir e perceber os fenômenos. Dessas relações resultam tanto uma identificação com quem nos cerca, como uma diferenciação restrita entre o "nós" e o "eles". A identificação assegura saber quem somos e a diferenciação evita que nos confundamos com os demais. Para Iñiguez, os conflitos intergrupais surgem em parte por conta deste paradoxo.

Em linhas gerais, a teoria da identidade social consiste em uma perspectiva das relações intergrupais que integra o comportamento individual ou interpessoal com os processos sociais e contextuais visando o entendimento dos conflitos intergrupais, e por isso os conceitos de categorização e comparação social aparecem articulados. Assim, considerando que a identidade social está associada ao conceito de pertença grupal, evocado pela categorização social, o significado emocional e avaliativo resultante dessa pertença deriva no favoritismo do endogrupo em detrimento do exogrupo (Tajfel \& Turner, 1979). 
É importante destacar que o processo de categorização social, base da construção da identidade social, fundamenta-se nas semelhanças intracategorias e nas diferenças entre as categorias. O que implica referir que desde a origem dos estudos sobre a identidade social, já era possível de se verificar que dentro dos grupos existem forças invisíveis extremamente potentes no sentido de enviesar a percepção e o julgamento dos membros (Tajfel, 1981). Um dos fenômenos que está associado a este processo é o efeito de acentuação, que consiste em acentuar as semelhanças ou diferenças de objetos ou pessoas em função de sua pertença categorial, podendo ocorrer o efeito de assimilação (análise dos objetos ou pessoas de uma mesma categoria) ou o efeito de contraste (análise dos objetos ou pessoas pertencentes a categorias distintas).

Para chegar a essas conclusões, Tajfel e Wilkes (1963) realizaram um estudo cujo objetivo consistiu em analisar se de fato os itens de uma mesma categoria são percebidos por meio do aumento das semelhanças entre si e se os itens de categorias diferentes passam pelo processo contrário, ou seja, são avaliados por meio do aumento das diferenças. Neste estudo, linhas verticais são apresentadas aos participantes em uma sequência, uma a uma e por repetidas vezes. As linhas possuem tamanhos diferentes e cabe aos participantes avaliar o comprimento das linhas. Três condições experimentais são manipuladas neste estudo. Em uma das condições, as quatro linhas maiores são denominadas de $\mathrm{A}$ e as menores de $\mathrm{B}$. Na outra condição, as linhas não possuem rótulos. Na última condição, os rótulos não possuem relação com os tamanhos das linhas. Pode-se verificar que na primeira condição, os participantes consideraram as linhas rotuladas de A e B como significativamente mais diferentes do que os participantes das outras condições. Com isto, Tajfel e Wikes puderam evidenciar que as classes distintas foram avaliadas tendo como pressuposto a saliência das diferenças entre elas.

Corneille, Klein, Lambert e Judd, (2002) replicaram o estudo clássico de Tajfel e Wilkes e suas evidências permitiram uma confirmação dos pressupostos já estimados. A acentuação categorial é maior em contextos onde as linhas são sistematicamente categorizadas do que em contextos onde a categorização prévia não existe. Adicionalmente, os autores puderam encontrar que em situações ambíguas, no caso deste estudo, em situações em que os participantes utilizavam medidas desconhecidas, por exemplo, belgas usavam polegadas e americanos centímetros, o efeito da acentuação foi mais forte.

Este efeito encontrado no nível perceptivo de objetos físicos estabelece um certo padrão quando se avalia a percepção de estímulos de outra ordem, como a percepção referente às relações intergrupais. Tajfel e colaboradores puseram então à prova os dados 
obtidos sobre a categorização de objetos físicos, investigando como se dá esse processo direcionado à percepção de pessoas.

Tajfel, Sheikh, e Gardner (1964) testaram suas novas hipóteses em participantes canadenses que deveriam emitir julgamentos sobre dois grupos distintos compostos por pessoas de mesma nacionalidade, um composto por dois jovens canadenses e outro composto por dois jovens indianos. Neste estudo, os participantes questionavam durante algum tempo os sujeitos dos grupos e analisavam suas opiniões sobre filmes e livros. Era solicitado a eles que descrevessem, por meio de um diferencial semântico ou de uma lista de adjetivos, os membros das duas nacionalidades. Os resultados demonstraram que os participantes julgaram os dois grupos de formas diferentes. Em relação ao grupo de indianos, os jovens superestimaram os atributos estereotípicos mais comuns das pessoas indianas, enquanto que para julgar o grupo de canadenses os traços mais típicos que remetem aos estereótipos deste grupo-alvo não foram superestimados. Ademais, os mesmos padrões do julgamento de objetos físicos foram encontrados no julgamento social: os membros da mesma nacionalidade são percebidos como mais semelhantes do que os membros das nacionalidades diferentes.

De acordo com Miranda (1998), caso extrapolemos essa conclusão para o plano social e consideremos que a classificação é feita em termos de critérios étnicos ou raciais e que a dimensão contínua se refere a atributos pessoais, as conclusões podem ser análogas. No entanto, supõe-se que a categorização social pode se apresentar de forma distinta, enquanto que no plano físico ela é neutra, em relação a grupos e pessoas pode se apresentar carregada de valoração. Com efeito, a questão da categorização social está em Tajfel, intrinsecamente associada à discriminação social. A discriminação como sendo um tratamento desfavorável em relação a indivíduos pertencentes a determinados grupos sociais é, segundo os pressupostos de Tajfel, um comportamento universal, tanto quanto o favoritismo dirigido ao próprio grupo de pertença.

Tajfel, Billig, Bundy e Flament (1971) publicam um estudo inserindo a questão do favoritismo endogrupal como fenômeno pertinente às relações intergrupais. Os autores objetivaram avaliar os efeitos da categorização social no comportamento intergrupal quando, na situação intergrupal, não estavam presentes nem interesses individuais, nem atitudes de hostilidade previamente determinadas. $\mathrm{Na}$ parte inicial do experimento, adolescentes do sexo masculino realizavam uma tarefa de julgamento estético. Em seguida, os adolescentes foram separados em dois grupos em função dos resultados obtidos na primeira tarefa, e eram requeridos a tomar decisões sobre a remuneração merecida para os membros do próprio grupo ou do outro grupo pela participação no experimento com o auxílio de matrizes de pagamento. Os resultados demonstraram que 
a mera separação ou categorização dos participantes em grupos diferentes é capaz de gerar a discriminação frente o exogrupo. O tipo de estratégia para a remuneração que influenciou os resultados foi "diferença máxima em favor do endogrupo", seguida pela estratégia "lucro máximo para os membros do endogrupo". A estratégia "máximo lucro comum", que repartia os lucros igualmente para o endogrupo e exogrupo, não se apresentou significativa e a estratégia "justiça" moderou o favoritismo ao endogrupo. Esses dados indicam que mais do que utilizar estratégias que permitam um ganho econômico para o endogrupo, os participantes entram em estado de competição com o exogrupo, melhor dizendo, esse estudo e demais realizados sob o comando de Tajfel, constatam que de modo bastante consistente a categorização é suficiente e atua de forma isolada como meio de determinar o favoritismo endogrupal e a rejeição frente exogrupos.

Esses estudos de Tajfel foram designados como modelo ou paradigma do grupo mínimo por consistirem em uma situação intergrupal experimental de onde são retiradas todas as variáveis que geralmente condizem à discriminação e ao favoritismo endogrupal, tais como, interação face a face, conflito de interesse, hostilidade prévia entre os grupos ou qualquer relação entre as respostas dos sujeitos e seus interesses pessoais. Estudos posteriores apresentam resultados consistentes (Chen \& Li, 2009; Charness, Rigotti \& Rustichini, 2007; Montalan, Lelard, Godefroy, \& Mouras, 2012).

Como pode ser avaliado, mesmo sem as variáveis comumente eliciadoras de estímulos intergrupais negativos, é possível se gerar o conflito intergrupal. Contudo, diferenciação intergrupal não é um simples produto de um conflito de interesses, mas emerge da necessidade principal de atribuir significado ao status intergrupal, de forma a fortalecer a identidade social, aumentando as diferenças entre os grupos ou criando diferenças que, de fato, não existem (Álvaro \& Garrido, 2003). As preferências demonstradas nos estudos sobre grupo mínimo podem representar um padrão de resposta em relação à percepção de diferenças sociais, no entanto, este é apenas um processo dentre outros diversos que interferem no julgamento e comportamento social (Dunham, Baron, \& Carey, 2011; Roberts, 2015).

Tajfel (1981) considera que o comportamento social pode ser entendido a partir de um continuum - de um lado estaria o nível puramente interpessoal, referindo qualquer encontro entre duas ou mais pessoas em que a interação é determinada pelas relações pessoais e pelas características pessoais respectivas e, de outro lado, o nível puramente intergrupal, em que todo o comportamento de dois ou mais indivíduos é determinado pela pertença a grupos diferentes. Desta forma, o nível interpessoal se relaciona à interação entre dois ou mais indivíduos derivada de suas características individuais ou 
relações pessoais, não sofrendo efeito da pertença grupal. O nível intergrupal corresponde à interação entre indivíduos ou grupos inteiramente influenciada pela pertença grupal, não sendo afetada pelas características individuais ou relações pessoais. Apesar desta conceitualização dicotômica acerca do processo de relações intergrupais, é importante ressaltar que não é provável que esse processo ocorra a partir de um dos níveis isolados na vida real, sobretudo, o interpessoal (Tajfel, 1981). Cabecinhas (2002a) acrescenta que, em relação a este continuum, Tajfel preocupou-se com as condições que determinam a adoção de formas de comportamento social que estejam mais próximas de um extremo ou de outro. Por exemplo, as condições que circundam o conflito intergrupal. Quanto mais intenso é um conflito, maior será a probabilidade de que os membros dos grupos se comportem afetados por suas pertenças grupais, mais do que afetados por suas características individuais ou relações interpessoais. Por outro lado, um conflito institucionalizado ou explicitamente de interesses intergrupais, não é suficiente para explicar as diversas situações em que o comportamento dos indivíduos de grupos distintos se aproxima do extremo intergrupal.

Em acréscimo, Tajfel (1981) coloca o extremo interpessoal como incoerente, quando pensado isoladamente, pois parece improvável, no contexto de interação entre duas pessoas, que essas não sejam afetadas por suas pertenças mútuas numa variedade de categorias sociais a partir das quais expectativas são construídas em relação as suas características e ações. Sendo o outro extremo, o comportamento puramente intergrupo, empiricamente menos arbitrário. Como exemplo, o autor cita uma tripulação da força aérea que bombardeia um alvo de população inimiga. Neste caso, o comportamento intergrupo parece conduzir a ação, no entanto, não é provável que aspectos do extremo interpessoal também não estejam presentes (Marvakis, 2015).

Para Tajfel (1981), a base dessas distinções entre comportamento interpessoal ou intergrupal, consiste em que no primeiro caso, os indivíduos agem enquanto indivíduos e, no segundo caso, os indivíduos interagem segundo suas pertenças de grupo. Assim, a condição básica para o aparecimento de comportamentos extremos intergrupo é a crença de que as fronteiras sociais relevantes entre os grupos são imutáveis, sejam quais forem as razões é impossível que os indivíduos de um grupo se movam para outro grupo. Do mesmo modo, a condição básica para o comportamento puramente interpessoal de indivíduos que se incluem em grupos distintos, é a crença de que as mesmas fronteiras intergrupais relevantes são flexíveis, mas que há grandes dificuldades que impedem a mobilidade social de indivíduos de um grupo para o outro. 
Desta forma, Tajfel (1981) enumera quatro atributos psicológicos sociais que determinarão possíveis formas de comportamento social: (1) o consenso entre os grupos envolvidos de que os critérios de estratificação são tão legítimos como estáveis (impossíveis de se alterar); (2) o consenso de que os critérios não são legítimos nem impossíveis de se alterar; (3) o consenso de que os critérios são ilegítimos, mas imutáveis por conta, por exemplo, de grandes diferenças de poder entre os grupos; (4) o consenso de que os critérios são legítimos, mas instáveis (possíveis de se alterar).

A combinação de ilegitimidade com instabilidade é capaz de incitar tentativas de mudança do status quo intergrupal, ou de resistência a tais mudanças por parte dos grupos que se sentem ameaçados por tais mudanças, ou seja, a transposição da linha divisória de um conflito latente para um conflito extremo e explícito pode ser o resultado desta combinação. De qualquer forma, a percepção de ilegitimidade ou de instabilidade de estratificações intergrupais por si, pode também gerar tentativas de mudar a situação intergrupal que podem culminar em resultados sistematicamente semelhantes aos resultados prováveis dos dois critérios em conjunto.

É neste sentido que Tajfel apresenta um continuum entre mobilidade social e mudança social. A mobilidade social define uma estruturação subjetiva de um sistema social cujo pressuposto está na flexibilidade e permeabilidade do sistema que permite um movimento inteiramente livre de um grupo para o outro. A mudança social, por sua vez, refere-se à crença do indivíduo de que está cercado pelas paredes do grupo social de que faz parte, logo, não pode deslocar-se do seu grupo para outro a fim de melhorar ou mudar sua posição (Tajfel, 1981). Santos e Amâncio (2014) apontam que o fator que pode determinar as formas de agir de membros de grupos desfavorecidos frente à desigualdade, por exemplo, é a sua percepção da estrutura intergrupal, caso seja percebida como ilegítima ou instável, pode contribuir para a consciência de alternativas de mudança à estrutura intergrupal existente, o que levará a uma diversidade de respostas coletivas para melhorar a posição do grupo. Por outro lado, a ausência de consciência de alternativas conduzirá apenas a buscas individuais de mudança ou a aceitação da condição desfavorável.

Tajfel acrescentou ainda que o estatuto dos grupos influencia as formas de comportamento intergrupal. Por estatuto grupal entendese a avaliação percebida em termos de uma hierarquia resultante de uma comparação social (Tajfel, 1981). No processo de julgamento e de interação social, os membros do grupo estão sujeitos a seguirem os conteúdos avaliativos e normativos comuns ao seu próprio grupo. O comportamento dos sujeitos em relação ao endogrupo e aos grupos que julgam relevantes na sociedade é orientado pela referência a normas e valores que a categorização social dá significado, por essa 
razão, as normas contextuais estão implicadas no conceito que as pessoas fazem do próprio grupo e do grupo alheio (Codol, 1984; Martins \& Gomes, 2011). Em resumo, a pertença grupal associada às normas do grupo em função da comparação social são os elementos que em conjunto determinam o julgamento e o comportamento social das pessoas.

Muito embora Tajfel e Turner (1979) tenham enfatizado que o modelo da identidade social leva em conta a realidade social e os aspectos dela resultantes, posto que argumentam que as variáveis psicossociais são derivadas de processos econômicos, políticos e sociais, alguns autores criticaram esse modelo justo no que se refere ao aspecto ideológico (Cabecinhas, 2002a; Monteiro, Lima, \& Vala, 1991). Conforme as críticas assinalam, a ideologia parece não fazer parte dos achados pertinentes aos estudos dos grupos mínimos. A universalidade com que o processo de favoritismo endogrupal opera no interior dos grupos ou a busca pela distintividade positiva do endogrupo implica em negligenciar as representações ideológicas das relações intergrupais (Judd \& Park, 2005; Scandroglio et al., 2008). Alguns autores põem em dúvida também a validade externa do paradigma do grupo mínimo indicando que, dentre outras questões, a própria estrutura da tarefa que define uma única dimensão possível de distintividade entre os grupos, impede que os indivíduos selecionem uma estratégia alternativa de comportamento intergrupal, restando apenas o desenvolvimento de condutas discriminatórias. Existe um conjunto de trabalhos que defendem a influência de múltiplos fatores sobre as estratégias escolhidas pelos grupos, condicionando apenas a algumas situações específicas, 0 aparecimento da discriminação intergrupal (Scandroglio et al., 2008). Modelos posteriores foram desenvolvidos no sentido de avançar nos aspectos apontados como limitantes da teoria da identidade social. Dentre eles, o modelo da auto-categorização, que diferentemente do modelo da identidade social, enfatiza o papel do self nos processos das relações intergrupais (Turner \& Onorato, 1999). Para esse modelo, a pertença a uma categoria específica se torna cognitivamente predominante na auto-percepção, guiando a percepção como um todo e o comportamento das pessoas (Sindic \& Condor, 2014). Turner, Hogg, Oakes, Reicher \& Wetherell (1987) apontaram que a saliência de uma determinada categorização não pode ser descrita como efeito de uma proeminência perceptiva automática de certos estímulos, mas depende do equilíbrio entre acessibilidade relativa (rapidez com que uma determinada categoria se faz presente cognitivamente em uma situação de interação social) e ajuste (grau em que a categorização consegue uma representação adequada da situação social). Para a teoria da auto-categorização, as pessoas representam os grupos sociais em termos de protótipos, entendendo estes como a representação subjetiva dos atributos 
definidores que são ativamente construídos e dependentes do contexto (Turner \& Reynolds, 2011). O julgamento social partiria do ponto de referência do self do observador, mas estaria também vinculado à saliência dos atributos pertinentes ao alvo de julgamento, daí o incremento dos estereótipos na percepção e julgamento social.

A teoria da auto-categorização consiste em uma teoria geral dos processos intergrupais e serve de base para a compreensão de outros fenômenos, tais como, a atração, a cooperação e a influência social, ademais, tem sido utilizada nos estudos sobre julgamento social e estereótipos (Turner \& Onorato, 1999; Turner, Oakes, Haslam \& McGarty, 1994). Não obstante à amplitude de investigações nesta perspectiva (Scandroglio et al., 2008), uma das limitações mais assinaladas na literatura a respeito deste modelo consiste no fato de seus pressupostos levarem em conta um "certo reducionismo psicológico" na explicação dos processos intergrupais (Cabecinhas, 2002b). Outras propostas têm buscado complementar os aspectos eminentemente cognitivos deste modelo, por exemplo, com elementos motivacionais, ou com elementos em um nível mais situacional e estrutural, como os modelos de distintividade ótima, diferenciação categorial, dentre outros (Sacandroglio et al., 2008).

A teoria da identidade social e a teoria da auto-categorização, muito embora tenham recebido críticas, permanecem sendo perspectivas de grande relevância no estudo dos processos grupais. Particularmente a teoria da identidade social tem dominado o campo de estudo das relações intergrupais nos últimos 30 anos (Huici, Gómez \& Bustillos, 2008), dada suas contribuições substanciais para a compreensão do comportamento social e dos fenômenos pertinentes às relações intergrupais. Como defendem Scandroglio e seus colegas (2008), "esta perspectiva pode ser especialmente pertinente ao oferecer um marco que conceitualiza as categorias sociais não como elementos estáticos ou performados vinculados à mente dos sujeitos, mas sim como emergentes que se constroem no momento da interação." ( $p$. 87).

Como podemos observar, os estudos seminais na perspectiva da teoria da identidade social puderam demonstrar que as relações intergrupais se estabelecem a partir da identidade social e que a relação entre a avaliação do próprio grupo e dos exogrupos constituem a origem do processo de categorização social que resulta muitas vezes no preconceito. Observamos também que a identidade social torna saliente o conjunto normativo que existe dentro do grupo e que este processo está associado ao julgamento social, o que, por sua vez, determina o poderoso papel que o contexto normativo assume nas relações intergrupais. Nesta linha de pensamento, enfatizamos a necessidade da articulação de diferentes níveis de análise para uma melhor compreensão dos fenômenos ligados às relações intergrupais, como é o caso do fenômeno do preconceito. 


\section{Considerações finais}

Chamamos a atenção no início deste artigo para alguns aspectos importantes das relações intra e intergrupais, vivenciados pelas personagens da fábula de Orwell, e utilizados como referência para uma discussão sobre as relações intergrupais. Percebemos que a constituição dos grupos se inicia com base em alguns determinantes psicossociológicos articulados aos processos de formação da identidade, comparação e categorização social, assim como, determinantes relativos ao contexto imediato que servem de palco para essa construção, como por exemplo, o convívio comum, a vivência da cooperação intragrupal e competição intergrupal, a necessidade de coesão para o alcance das metas, dentre outros. Deste modo, tal como na Granja Solar, os sujeitos se organizam em grupos com a finalidade de se fazerem efetivos em seus propósitos e metas, e com isso uma diversidade de processos grupais emergem. Tais processos funcionam como agentes propulsores das barreiras que diferenciam um grupo do outro, e podem gerar desde uma separação concreta entre o "nós" e o "eles" amistosa e pacífica, a conflitos segregacionistas e ódio intergrupal. É neste ponto que compreender a origem dos sentimentos de grupo se faz importante para uma reflexão acerca do preconceito e da discriminação social.

Sobre o desenvolvimento da pertença grupal, foi possível evidenciar que esse sentimento de pertencer ao grupo, ou seja, esse anseio de fazer parte, de estar inserido, constitui-se como base para a construção tanto da identidade social como das formas de conduta no quadro das relações interpessoais e intergrupais. Naturalmente o sentimento de pertença é desenvolvido por meio da interação social e a avaliação desse sentimento pertinente à comparação social está no centro das emoções e crenças auto-dirigidas. Tajfel (1981) defende que a estima subjetiva referente à pertença social é fundamental para derivar o comportamento das pessoas diante das relações intergrupais, daí a estreita vinculação entre preconceito e identidade social.

Para Allport (1962), o preconceito parte de uma ideia apressada e injustificada que se manifesta contra as pessoas de grupos percebidos como inferiores. As pessoas são julgadas por suas pertenças grupais, e com isto, generalizações exageradas são construídas sobre as características das pessoas pertencentes aos grupos, portanto, o processo de categorização social pode ser destacado com um dos principais responsáveis pelo favoritismo endogrupal e a discriminação exogrupal. As pesquisas neste aporte demonstram o quanto grupos que se unem sem nenhum critério de identificação prévio podem desenvolver o favoritismo endogrupal e o antagonismo exogrupal, ressaltando-se que, para ocorrer esta 
oposição, também foi constatado que não há a necessidade da existência de conflitos precedentes entre esses grupos.

$\mathrm{Na}$ Granja Solar, os grupos foram se organizando e posteriormente se segregando em função de objetivos comuns. Observa-se a construção de normas e os sentimentos que emergem da convivência entre os grupos. Podemos perceber que o processo de comparação social articulado à identidade social, aparece no início do conflito entre animais e humanos e segue fazendo parte do repertório cognitivo e comportamental das personagens ao constituírem a diferenciação em grupos dos próprios animais: porcos de um lado e os demais animais do outro. Segundo os pressupostos de Tajfel, a combinação de ilegitimidade e instabilidade das configurações e barreiras intergrupais é capaz de gerar no indivíduo ou grupo a busca por mudanças ou seu oposto, a resistência (a mudança seria desejada pelos descontentes com a configuração dos grupos e a resistência seria aspirada pelos satisfeitos com essa configuração). Desta forma, o que pode determinar as formas de agir de grupos desfavorecidos em busca dessas mudanças consiste na percepção da estrutura intergrupal, o que, através da consciência da existência de alternativas, provoca respostas coletivas em prol dessas mudanças. Contudo, não havendo a percepção de alternativas, a possibilidade de conformação do grupo com a condição desfavorável é um dado relativamente esperado (Santos \& Amancio, 2014), como ocorreu com os animais regulados pelos porcos da Granja Solar. Assim, de modo semelhante à vida real, sugerimos o estudo desses processos como meios de lançar um olhar mais abrangente aos fenômenos do preconceito e da discriminação social, contudo, não os definindo como elementos estáticos, mas como processos mutáveis, derivantes de uma teia de interações experienciadas no cenário das relações sociais, que por natureza, estão em permanente movimento.

\section{Referências}

Allport, G. W. (1962). La naturaleza del prejuicio. Argentina: UEDEBA.

Álvaro, J. L. \& Garrido, A. (2003). Psicologia social - perspectivas psicológicas e sociológicas. São Paulo: McGraw-Hill.

Amâncio, L. (1993). Níveis de análise no estudo da identidade social. Análise psicológica, 2(9), 213-221.

Brasil, J. A., \& Cabecinhas, R. (2014). Processos Identitários, Representações Sociais e Migrações: Reflexões sobre a I dentidade Latino-Americana. CECS-Publicações/eBooks, 123138. 
Cabecinhas, R. (2002a). Media, etnocentrismo e estereótipos sociais. In As Ciências da Comunicação na Viragem do Século. Actas do I Congresso de Ciências da Comunicação, 407-418.

Cabecinhas, R. (2002b). Media, etnocentrismo e estereótipos sociais. In As Ciências da Comunicação na Viragem do Século. Actas do I Congresso de Ciências da Comunicação, 407-418.

Cabecinhas, R. \& Lázaro, A. (1997). Identidade Social e Estereótipos Sociais de Grupos em Conflito: Um Estudo numa Organização Universitária. Cadernos do Noroeste, 10(1), 411-426.

Charness, G., Rigotti, L., \& Rustichini, A. (2007). Individual Behavior and Group Membership. American Economic Review, 97, 13401352.

Chen, R., \& Chen, Y. (2011). The potential of social identity for equilibrium selection. American Economic Review, 101, 25622589.

Chen, Y. \& Li, S. (2009). Group Identity and Social Preferences. American Economic Review, 99, 431-457.

Christian, J., Bagozzi, R., Abrams, D., \& Rosenthal, H. (2012). Social influence in newly formed groups: The roles of personal and social intentions, group norms, and social identity. Personality and Individual Differences, 52(3), 255-260.

Cikara, M., Botvinick, M. M., \& Fiske, S. T. (2011). Us versus them social identity shapes neural responses to intergroup competition and harm. Psychological science.

Codol, J. P. (1984). On the system of representations in an artificial social situation. In R. Farr \& S. Moscovici (Orgs.). Social representations. Cambridge: University Press, 239-253.

Corneille, O., Klein, O., Lambert, S., \& Judd, C. M. (2002). On the role of familiarity with units of measurement in producing categorical accentuation: Tajfel and Wilkes (1963) revisited and replicated. Psychological Science, 4, 380-383.

Costa, W. S. D. (2009). Na procura do país irmão, o encontro com o primo distante. Significados atribuídos à experiência de imigração por mulheres brasileiras no Distrito do Porto (Tese de doutorado acessada em http: // repositorium. sdum. uminho. pt/ bitstream/1822/14218/1/T ESE.pdf).

Doise, W. (2002). Da psicologia social à psicologia societal. Psicologia: teoria e pesquisa [online], 18(1), 27-35.

Dunham, Y., Baron, A. S., \& Carey, S. (2011). Consequences of "minimal" group affiliations in children. Child Development, 82(3), 793-811.

Gaertner, S. L., \& Dovidio, J. F. (2000). Reducing intergroup bias: The common ingroup identity model. Philadelphia, PA: The Psychology Press. 
Huici, C., Gómez, A. \& Bustillos, A. (2008). La identidad comparativa veinte años después: repercusión en el dominio de las relaciones intergrupales. Revista de Psicología Social, 23(3), 297-313.

Iñiguez, L. (2001). Identidad: de lo personal a lo social. Un recorrido conceptual. In E. Crespo \& C. Soldevilla (Orgs.). La constitución social de la subjetividad. Catarata: Madrid, 209-225.

Jenkins, R. (2014). Social identity. New York. Routledge.

Judd, C. M. \& Park, B. (2005). Group Differences and Stereotype Accuracy. In J. F. Dovidio, P. Glick, \& L. A. Budman (Eds.). On the Nature of Prejudice (pp. 123-138). Oxford: Blackwell Publishing.

Levine, R. A. \& Campbell, D. T. (1972). Ethnocentrism: Theories of conflict, ethnic attitudes, and group behaviour. Nova Iorque: J ohn Wiley \& Sons.

Lewin, K. (1997). Self-Hatred Among Jews (1941). American Psychological Association.

Martins, J., \& Gomes, P. S. (2011). Identidade, desvio e reputação no grupo de pares. Antropológicas, (12), 67-73.

Marvakis, A. (2015). The dialectics of new fascism in Greece. Estudos de Psicologia (Campinas), 32(3), 547-556.

Miranda, J. (1998). Comportamento intergrupal - revisão da literatura. Análise Psicológica, 4(XVI), 599-614.

Montalan, B., Lelard, T., Godefroy, O., \& Mouras, H. (2012). Behavioral investigation of the influence of social categorization on empathy for pain: a minimal group paradigm study. Frontiers in Psychology, 3, 389.

Monteiro, M. B., Lima, M. L., \& Vala, J. (1991). I dentidade social. Um conceito chave ou uma panacéia universal. Sociologia: problemas e práticas, 9, 107-120.

Neto, M. M. \& Amâncio, L. (1997). Algumas estratégias identitárias dos algarvios face o impacte do turismo uma abordagem psicossociológica. Revista ESGHT - UAL, 2(2), 31-38.

Orwell, G. (1989). Animal Farm. 1945. Online edition: http://www.msxnet.org/orwell/print/animal_farm.pdf (acessado em abril de 2017).

Roberts, J. A. (2015). Investigating Minimal Group Bias \& Equality Preference in Children's Resource Allocation Tasks. Honors Theses, Wesleyan University, Middletown, Connecticut, United States. Retrieved October 5, 2015, from http://wesscholar.wesleyan.edu/etd_hon_theses/1354

Santos, M. H., \& Amâncio, L. (2014). Perceção de justiça, discriminação e sexismo. Psicologia, 28(1), 63-76.

Scandroglio, B., Martínez, J. S. L., \& Sebastián, C. S. J. (2008). La teoría de la identidad social: Una síntesis crítica de sus 
fundamentos, evidencias y controversias. Psicothema, 20(1), 8089.

Sherif, M. (1961). The Robbers Cave experiment: Intergroup conflict and cooperation. Wesleyan University Press.

Sherif, M., Taub, D., \& Hovland, C. I. (1958). Assimilation and contrast effects of anchoring stimuli on judgments. Journal of Experimental Psychology, 55(2), 150.

Sindic, D., \& Condor, S. (2014). Social Identity Theory and SelfCategorization Theory. The Palgrave Handbook of Global Political Psychology, 39.

Tajfel, H. (1981). Grupos humanos e categorias sociais. Lisboa: Livros Horizonte.

Tajfel, H., Billig, M. G., Bundy, R. P., \& Flament, C. (1971). Social categorization and intergroup behaviour. European journal of social psychology, 1(2), 149-178.

Tajfel, H., Sheikh, A. A., \& Gardner, R. C. (1964). Content of stereotypes and the inference of similarity between members of stereotyped groups. Acta Psychologica, 22, 191-201.

Tajfel, H., \& Turner, J. C. (1979). An integrative theory of intergroup conflict. In W. G. Austin \& S. Worchel (Eds.). The social psychology of intergroup relations. Monterey, CA: Brooks/Cole, 33-47.

Tajfel, H., \& Wilkes, A. L. (1963). Classification and quantitative judgement. British J ournal of Psychology, 54(2), 101-114.

Turner, J. C., Hogg, M. A., Oakes, P. J., Reicher, S. D., \& Wetherell, M. S. (1987). Rediscovering the social group: A selfcategorization theory. Basil Blackwell.

Turner, J., Oakes, P., Haslam, S, A., \& McGarty, C. (1994). Selfand collective: Cognition and social context. Personality and social psychology bulletin, 20, 454-463.

Turner, J. C., \& Onorato, R. (1999). Social identity, personality and the self-concept: A selfcategorization perspective. In T. R. Tyler, R. M. Kramer, \& O. P. John (Eds.). The psychology of the social self ( $p p$. 11-46). Mahwah: Lawrence Erlbaum Associates.

Turner, J. C., \& Reynolds, K. J. (2011). Self-categorization Theory. In In Van Lange, Kruglanski, \& Higgins (Eds.). Handbook of Theories in Social Psychology (pp. 399-417). London: Sage Publications.

\section{Endereço para correspondência}

\section{Sheyla Christine Santos Fernandes}

Universidade Federal de Alagoas - UFAL

Instituto de Psicologia - Programa de Pós-Graduação em Psicologia

Av. Lourival Melo Mota, s/n, Tabuleiro do Martins, CEP 57072-900, Maceió - AL, Brasil

Endereço eletrônico: sheyla.fernandes@ip.ufal.br 


\section{Marcos Emanoel Pereira}

Universidade Federal da Bahia

Instituto de Psicologia

Estrada de São Lázaro, 197, Federação, CEP 40210 730, Salvador - BA, Brasil

Endereço eletrônico: memanoel@gmail.com

Recebido em: 22/10/2015

Reformulado em: 02/05/2017

Aceito em: 08/08/2017

\section{Notas}

* Doutora em Psicologia Social pelo Programa de Pós-Graduação em Psicologia Social da Universidade Federal da Bahia, professora do Instituto de Psicologia da Universidade Federal de Alagoas.

** Doutor em Psicologia Social pela Universidade Federal do Rio de Janeiro, professor do Instituto de Psicologia da Universidade Federal da Bahia.

Este artigo de revista Estudos e Pesquisas em Psicologia é licenciado sob uma Licença Creative Commons Atribuição-Não Comercial 3.0 Não Adaptada. 